\title{
KNOWLEDGE AND PRACTICES GOVERNING THE IMPLEMENTATION OF NASOGASTRIC TUBE FEEDING AS A TEMPORARY UNDERNUTRITION MANAGEMENT MEASURE IN ACUTE GERIATRIC CARE: A QUALITATIVE RESEARCH-BASED ANALYSIS
}

\author{
E. Fercot ${ }^{1}$, L. Marty ${ }^{2}$, C. Bouteloup 3 , Y. Lepley ${ }^{4}$, J. Bohatier ${ }^{1}$, M. Bonnefoy ${ }^{4}$, B. Lesourd ${ }^{5}$, Y. Boirie B S. Dadet $^{7}$
}

\begin{abstract}
Introduction: Nasogastric tube feeding appears underused in acute geriatric care units. The objective of this study was to identify the knowledge, practice, fears or behaviors of care givers governing implementation. Material and Methods: Multicentric qualitative research study based on interviews with geriatricians and care staff. Coding of patterns and thematic analysis of the data were used to extract key concepts tied to the objective. Results: Ten geriatricians and eleven care staff were interviewed individually and in a focus-group setting. Undernutrition was perceived as a prognosis-worsening comorbidity, not a disease. Early screening for undernutrition appeared essential, but care management and monitoring was within the remit of downstream structures. A handful of indications are reported to justify moves to start nasogastric tube feeding, often as part of adjuvant care, when real benefit is expected, when the individualized feeding plan is part of a comprehensive care plan, with the patient consciously involved and after consulting with the family. Patients' fear of complications, cognitive disorders, and uncertain life expectancy often fuel concerns of a form of unreasonable obstinacy. Finally, doctors and care staff alike think that decisions on nasogastric intubation in this patient population require a multidisciplinary-team process. Conclusion: Nasogastric tube feeding in acute geriatric care remains fraught with issues. It looks a viable option, but should be part of a comprehensive care plan, based on multidisciplinary decision-making by appropriately-trained teams, where the goals of care are the patient's comfort and quality of life.
\end{abstract}

Key words: Enteral nutrition, frailty, care management, geriatrics, malnutrition, quality of life.

\section{Introduction}

According to French health authorities (HAS-Haute Autorite de Santé) figures, the prevalence of hospital undernutrition in France approaches $30-70 \%$ in patients over 80 years $(1,2)$. Acute illnesses increase proteinenergy needs, while intakes are often inadequate due to episodic loss of appetite, eating difficulties or malabsorption $(1,3)$. This deficit can lead to protein-

\footnotetext{
1. Gérontopôle, CHU Clermont-Ferrand, Clermont-Ferrand, France; 2. Anthropologue de la santé, Département de Médecine Générale, Université Clermont Ferrand Auvergne, Clermont-Ferrand, France; 3. Université Clermont Auvergne, INRA, UNH,Unité de Nutrition Humaine, CHU Clermont-Ferrand, Service de médecine digestive et hépatobiliaire, CRNH Auvergne, ClermontFerrand, France; 4. Université Claude Bernard Lyon 1, Faculté Lyon-Sud, France, Inserm U1060, Université Lyon 1, France, Service de médecine gériatrique, Hospices civils de Lyon, France; 5 . Université Clermont Auvergne, ClermontFerrand, France; 6. Université Clermont Auvergne, INRA, UNH, Unité de Nutrition Humaine, CHU Clermont-Ferrand, Service de Nutrition Clinique, CRNH Auvergne, Clermont-Ferrand, France; 7. Université Clermont Auvergne, INRA, UNH, Unité de Nutrition Humaine, CHU Clermont-Ferrand, CHU Clermont-Ferrand, Gérontopôle, CHU Clermont-Ferrand, France.
}

Corresponding Author: Elise Fercot, Gérontopôle, CHU Clermont-Ferrand, F-63000 Clermont-Ferrand, France, fercote@hotmail.fr energy undernutrition, which increases the risk of sarcopenia, frailty (4), loss of functional capabilities (5), infectious risk (6), length of stay at hospital (7) impair functional outcomes and recovery (8) and mortality $(9,10)$. Effective nutritional management is therefore necessary, and various academic societies have proposed strategies that include artificial nutrition $(1,11,12)$. These care decision strategies can be constructed as decision trees, such as that of the French society for clinical nutrition and metabolism (SFNEP), but are rarely adapted to very old patients (13). The HAS and the European society for clinical nutrition and metabolism (ESPEN) issued guidelines in 2006 and 2007 specifically addressing factors unique to geriatric care : patient life expectancy, functional capabilities, frailty, neurocognitive disorders and comorbidities $(1,12)$. In practice, while nasogastric tube (NGT) feeding for enteral nutrition (EN) may be recommended in acute-phase hospital care, it is a lot more problematic in the acute geriatric care unit (AGCU) (13) and reluctance for a enteral nutrition may exist because of lack of education, knowledge, communication, or team work (14). In an effort to improve nutrition management 
in these units, an improvement in a deeper understanding of the practices and of the difficulties among the clinicians and care staff teams is expected.

Therefore, the objective of the present study was to identify the knowledge and practices governing the implementation of NGT feeding in AGCU wards. The aim was to survey geriatric care professionals to capture their opinion on nutrition management, evaluate their knowledge of the issue, characterize their expectations and perceptions, and identify the reasons that frustrate or facilitate the process of prescribing NGT placement.

\section{Matherials and methods}

\section{Description of the study}

This multicentric qualitative research study was led in AGCU wards at different Main City Hospitals $(\mathrm{MCH})$ in the Auvergne region, France.

\section{Choice of method}

Qualitative research explores complex phenomena, arising from the 'human factor' of care delivery, in their natural environment. It attempts to make sense of the participant experiences and interpret the meanings they attribute to them. The process of analysis is approached inductively, in contrast to deductive approaches that systematically verify a pre-determined hypothesis. The method of inquiry used is based on the 32-item COREQ 2007 criteria, spanning 3 domains: research team and reflexivity, study design, and analysis and findings (15). Data was collected through semi-structured interviewseither individual or in focus-group format. Individual interviews give interviewees the freedom to open up and express themselves, while focus groups enable interaction based on group-effect dynamics and dialogue, thus facilitating the emergence of knowledge, opinion and experience by bringing different personal perspectives together. The open-ended questions addressed topics defined in an interview guide. People interviewed were free to address other concepts not initially agendaed. The study secured approval from the local French ethics committee ('CPP' Sud-Est VI) for the protection of human subjects.

\section{Sampling}

The sample of geriatric doctors and care staff (Registered Nurses (RN) and Registered Nursing Care Assistants (RNCA))-all of whom were volunteers-had to be heterogeneous in order to capture the broadest possible range of opinions, experiences and practices. Age, gender, place of practice, career path, time in the job, and further training and education had to be as varied as possible. We continued to include material until thematic saturation.

\section{Interview guide}

Two interview guides were developed and tested to fit each professional (one for doctors and one for care staff, both of which served for the individual interviews and the focus group) in order to explore the various themes exposed in the literature on enteral nutrition. The guides were modified after the early exploratory interviews, as the questions were not open-ended enough, which hinded in free-flowing conversation. Likewise, certain questions asking about the knowledge held by doctors and care staff were deleted to rule out any value judgment.

\section{Process and flow of the interviews}

The interviewers opened by explaining the aim of the interview or focus group and the objectives targeted. They then had the time to outline the interview process, guaranteeing that everything shared would be anonymous and confidential and in no way critical or judgemental. The interviewer then collected the credentials of the people interviewed and their consent to record the conversation.

a) Process and flow of a semi-structured individual interview:

The interview started with the interviewee telling their story of an experience-whether good or bad-with NGT feeding. The questions were then cued by the interview guide until all the themes had been addressed. The same interviewer, mainly at the participants' place of work, conducted all the interviews.

b) Process and flow of a semi-structured focus group:

The focus group was asked to talk over one or more experiences concerning NGT feeding. Two investigators were mobilized to take part in the focus group-one as facilitator, the other as observer to collect expressions of nonverbal communication. The moderator used a set of questions to keep dialogue and discussion focused, making sure that all the focal topics in the interview guide were addressed.

\section{Collection of the data material}

All the interviews were recorded end-to-end on an OLYMPUS-brand digital dictaphone. All digital capture was transcribed in depersonalized format into a verbatimrecord Microsoft Word document. No digital data records were kept.

\section{Method of analysis}

The process of thematic analysis based on verbatim accounts started right from the first interview. The 
Table 1

Doctor characteristics

\begin{tabular}{llllll}
\hline Doctor & Age & Gender & Experience in the AGCU & Training programs & Interview \\
\hline Doctor \#1 & 42 & $\mathrm{~F}$ & 5 years & Palliative care, Respiratory medicine & Individual \\
Doctor \#2 & 29 & $\mathrm{~F}$ & 2 years & Pressure ulcers & Individual \\
Doctor \#3 & 42 & $\mathrm{M}$ & 6 months & Clinical psychology-Neurocognitive disorders & Individual \\
Doctor \#4 & 53 & $\mathrm{M}$ & 20 years & Nutrition & Individual \\
Doctor \#5 & 47 & $\mathrm{M}$ & 5 years & Palliative care, Neurocognitive disorders & Focus group \\
Doctor \#6 & 30 & $\mathrm{~F}$ & 3 years & Geriatric oncology & Froup \\
Doctor \#7 & 54 & $\mathrm{~F}$ & 5 years & Palliative care, Psychiatry, geriatric psychology and psychogeriatrics & Focus group \\
Doctor \#8 & 47 & $\mathrm{~F}$ & 6 years & Dermatology Palliative care & Focus group \\
Doctor \#9 & 36 & $\mathrm{~F}$ & $11 / 2$ years & Antibiotics Emergency medicine & Focus group \\
Doctor \#10 & 32 & $\mathrm{M}$ & 5 years & Neurocognitive disorders & Individual \\
\hline
\end{tabular}

Table 2

Care staff characteristics

\begin{tabular}{llllll}
\hline Profession & Age & Gender & Experience in the AGCU & Training programs & Interviews \\
\hline $\mathrm{RN}^{1} 1$ & 40 & $\mathrm{M}$ & 2 years & & \\
$\mathrm{RN}^{1} 2$ & 42 & $\mathrm{~F}$ & 2 years & Neurocognitive disorders, Nutrition & Individual \\
$\mathrm{RN}^{1} 3$ & 37 & $\mathrm{~F}$ & 2 years & & Individual \\
$\mathrm{RN}^{1} 4$ & 25 & $\mathrm{~F}$ & $1 \frac{1}{2}$ years & & Individual \\
$\mathrm{NCA}^{2} 5$ & 46 & $\mathrm{~F}$ & 5 years & Abuse, Dental care & Individual \\
$\mathrm{NCA}^{2} 6$ & 50 & $\mathrm{~F}$ & $1 \frac{1}{2}$ years & Palliative care & Focus group \\
$\mathrm{RN}^{1} 7$ & 58 & $\mathrm{~F}$ & 3 years & Nutrition & Focus group \\
$\mathrm{RN}^{1} 8$ & 36 & $\mathrm{~F}$ & 6 years & Palliative care & Focus group \\
$\mathrm{NCA}^{2} 9$ & 39 & $\mathrm{~F}$ & 2 years & Communication-Interpersonal relations \\
$\mathrm{NCA}^{2} 10$ & 34 & $\mathrm{~F}$ & $\mathrm{~F}$ & 22 years & Focus group \\
$\mathrm{NCA}^{2} 11$ & 47 & $\mathrm{~F}$ & & Focus group \\
\hline
\end{tabular}

$\mathrm{RN}^{1}$ Registered Nurse, NCA ${ }^{2}$ Nursing Care Assistant

content of the verbalized conversation was collapsed into themes that were then subcategorized. The interview transcripts were then re-read and reviewed a second time using this list.

\section{Results}

\section{Description of the people interviewed}

The interviews were conducted from February to August 2015.

\section{Interviews with doctors}

Interviews were led in-hospital, in 5 different $\mathrm{MCH}$ including $4 \mathrm{AGCU}$, on the 10 geriatric doctors reported in Table 1, thus compiling 4h22 of recorded material. The sample was positively heterogeneous for age, gender, experience and place of practice. The focus of background training tended to be on palliative care and neurodegenerative diseases. Only one of the doctors had been university-trained on nutrition.

\section{Interviews with care staff}

Interviews were led in the same $\mathrm{MCH}$ hosting 3 different AGCU, on the 11 care staff reported in Table 2 , thus compiling $4 \mathrm{~h} 04$ of recorded material. Two participants were interviewed by phone and one at home. The sample was positively heterogeneous for age, gender, and professional experience. The most common focus of background training was palliative care and neurodegenerative diseases, and only two of the 11 care staff had been given training on nutrition. 


\section{Analysis of the main findings}

Various major themes and concepts emerged.

\section{Knowledge and training levels of the geriatric care professionals}

\section{$\underline{\text { Interviews with doctors }}$}

The geriatric doctors claim they are undertrained on nutrition. "You can't say 'trained'. You learn on the job." (Doctor \#5) "By our department heads and colleagues." (Doctor \#6)

\section{Interviews with care staff}

The RN feel undertrained on EN, especially on technical procedure. "I think the nurses in general don't know enough about placing the NGT, because, it's true, at nursing school you only get a brief look at it" (RN \#1) "Er, the training goes back 15 years ago [...] but the first one I got to place, that was later on, once I had started work" (RN \#2).

\section{Nutrition in hospital practice}

\section{Screening for undernutrition}

Screening appears to be a routine phase, but with different approaches. "It's a routine practice on the admission tests for all elderly subjects". (Doctor \#1) "Weight, height, body mass index chemistry panelsystematically" (Doctor \#4). The geriatricians also think they are more undernutrition-aware than other speciality practitioners. "We screen them as soon as they come in [...] We're optimal on that, we're in good shape"(Doctor \#1). However, there is variability in the resources mobilized for the nutritional status assessment, and the doctors voiced their issues, given how exhaustive investigation is just not feasible. "It's always made hard by the fact they already have some kind of inflammatory syndrome, so we struggle to quantify their baseline nutritional status" (Doctor \#3) "It only really starts getting useful if you've got past weight figures". (Doctor \#3). Close monitoring of food intakes is voiced more by the care staff, who also feel they are screening-aware. "We generally do the 3-day food and drink record chart" (RN \#3). "If they don't eat anything, there are written messages, verbal messages, it gets flagged up." (RNCA $\# 1)$.

\section{Management of undernutrition}

For the doctors, oral nutrition remains the best care plan going forward. "So if oral intake is possible, then you put them straight on oral nutritional supplements (ONS) already [...] you maintain oral feeding, which takes priority" (Doctor \#1). "In most cases, elderly patients are undernourished. So what I sometimes do is, rather than wait to get low blood Proteins, I put them straight on refeeding protocol with two ONS/day." (Doctor \#1) Certain hypercatabolic-syndrome settings nevertheless prompt them to start thinking oral nutrition is not enough. "When pressure ulcers or cancers come back, these situations where you know you need far higher intakes-where you have no time to lose." (Doctor \#2)

\section{Follow-up on undernutrition care throughout the hospital stay}

Some geriatricians feel that undernutrition management should be pushed back to later. "In the AGCU, you assess: the hospital stay is too short to re-assess your NS-backed feeding programme [...]. When you come to re-assess, they are often already be in Subacute Care and Rehabilitation (SCR)" (Doctor \#2). However, they do feel that they could also push their engagement further to prepare the ground for enteral feeding when the nutritional management rolls over into SCR "Say, OK, this patient has a severe undernutrition, to be re-assessed in $x$ amount of time and if not reversed, place the NGT." (Doctor \#2). The care staff, though, manifestly voice a disconnect between their routine nursing and the medical management process. "You do food record charts for people who are eating loads, and when you flag up that the person isn't eating, you don't do a food record chart [...] there's a gap there, and you tell yourself nothing gets done." (RNCA \#7)

\section{Elements considered for medical decision}

\section{Indications for NGT placement}

The doctors appear to share a consensus that it is essential to optimally feed patients admitted for pressure ulcer, dysphagia after a stroke, or to ready for surgery or chemotherapy. "After that, deep pressure ulcer might be an issue" (Doctor \#3) "a lady who had a haemorrhagic stroke, there it's undeniably a good indication [...] there is hope for recovery once the hematoma resorbs" (Doctor \#5) "It's presurgery nutrition to support better tolerance." (Doctor \#9). Anorexia against a background of depression with decline in general status also emerges as a consensus indication. "We were clearly looking at a care plan including antidepressants, and it worked out that way." (Doctor \#7). There is no clear consensus for infection management, even though the geriatricians appeared to recognize this indication. "I think that one of the best indications is to get through an acute-phase flare of infection or inflammation when you know it is 
likely to resolve." (Doctor \#3) This was voiced in the focus group without any objection from the co-attendees, and again in individual interview. "It's in situations of acute stress-where there are going to be difficulties over one week, difficulties getting enough intake during major hypercatabolism-may be situations like that where, from time to time, we could be proposing the patient artificial nutritional support, but we don't." (Doctor \#10)

\section{$\underline{\text { Patient information and consent }}$}

All the doctors interviewed uphold and respect the principle that the patient's wishes come ahead of any medical rationale. "Me, I work to the principle that if they are against it, then I don't fit it" (Doctor \#10). Many doctors reported that even when patients are fully informed and give their consent, they will still rip their NGT out eventually. "He ripped the catheter out, we offered to re-place it, and as he answered a very clear 'no', we didn't do it" (Doctor \#2) Over and above consent, the decisive factor is ultimately active patient participation. "A patient who was really engaged in cooperation, active collaboration, which makes everything so much easier [...] he really was a stakeholder in his own care plan". (Doctor \#5)

\section{Relationship with the family}

The family holds a central position as the primary caregivers to go through when communication or decision-making are out of the older patient's reach, when no advance care directives to go on. "She didn't want any artificial support, so we held off the enteral nutrition in accordance with the directive that the patient hadsupposedly-left but that her two daughters had passed on" (Doctor \#5). That said, the opinion of the caregivers can put the practitioner in a difficult position, under pressure from the family to provide an enteral nutrition that the practitioner sees as unreasonable. "The family is always all for it, because their perception is that the nutrition is what is going to save them" (Doctor \#10) Conversely, at other times, the family may be against an enteral nutrition that the doctor wants to implement. "We were pretty much pushing-and this was against the family's wishes-to keep the enteral feeding going, and what ultimately happened was that the patient almost completely recovered as she was able to resumed normal feeding." (Doctor \#5) Even if the family are a primary proxy in geriatrics, the patient remains the primary decision-maker. "He is cognitively healthy, so we don't need to call the family in-it's his decision." (Doctor \#1). There is a unanimous view that it is vital to inform the family to foster their acceptance and participation in care. "If you explain everything properly, there's no reason the family won't accept it. Information is actually the be-all and end-all." (Doctor \#3)

\section{Care-team decision-making}

A collegial forum is something that the doctors and especially the care staff want. "These are still tough decisions to make, so I do find that the staff meeting helps get a clear picture of the issues." (Doctor \#2) Care staff want to be involved in the decision process, to understand it, as their assessments sometimes diverge from those made by the doctors. "Us, the nurses and nursing care assistants, as a rule, it just gets done, no-one asks us for any input. You show up in the morning, NGTs have been placed without anyone asking us if it's a good idea, a bad idea" (RNCA \#6) "When you don't get consulted, you don't necessarily understand [...] whereas if you're involved, whether you agree with it or not, at least you can understand." (RNCA \#6)

\section{Benefits expected}

The doctors are unable to give a clear picture of the real benefit expected from NGT feeding as a nutrition support measure in this population. "What really clouds the issue is that we just can't properly measure the impact" (Doctor \#5) "My feeling would be that more often than not it's a failure" (Doctor \#3). There appears to be some kind of dichotomy between the confirmed need for a NGT and doubts over the benefit expected. "Is always reasoning in terms of the patient's best interests, over and above any biological formula or loss of weight, really going to bring them something?" (Doctor \#10).

\section{Importance of the care plan}

The comprehensive care plan approach is a mainstay of geriatric medicine. "Either way, more than any kind of across-the-board assessment, it's really going to be typically geriatric, [...] What do they want? Is it worth it?" (Doctor \#7) The majority of geriatricians was for including nutrition management and NGT feeding into a coherent comprehensive care plan as one of the factors of the parameters of geriatric patient assessment-qualityof-life included. "Geriatrics is never all about a nutrition plan. For me, it's always about a plan for the future, a plan to make it out of the acute-care period." (Doctor \#7) "What is the plan, what is the potential for recovery?" (Doctor \#5).

\section{Prescription practice influenced by geriatric- ward experience}

Those practitioners most exposed to care dependency and pathological aging are quick to confide how it may colour their thinking. "Personally I think I have been also conditioned by my experience of long-term hospital care $[\ldots]$ a dozen patients on enteral feeding for months, years sometimes, all spent fighting with the adverse effects $[. .$. 
I've seen all the negatives of extended enteral, the ethics conversations, the families who just want it all to stop". (Doctor \#5) "Often, with the patients we have here at the AGCU, it's hard to really go for it when you know the complications" (Doctor \#2).

\section{Barriers to implementing EN}

\section{Factors connected to the geriatric care environment}

\section{Preconceptions and perceptions of geriatricians}

The perception seems to be that undernutrition is a comorbidity rather than an independent disease, and the doctors anticipate how patients will react to a problem they often ignore. "The patient's going to turn round and say 'but I've got no complaint. All I want is to not be in pain, the infection is under control, and right now I don't feel I'm suffering from undernutrition" " (Doctor \#5) As a rule, the geriatricians feel that they do start thinking about EN, but often too late on. "Let's just say that if you start asking yourself whether you should be putting them on it, then it's that things are already a bit desperate." (Doctor \#3) This delay may be explained by their doubts over the benefit expected and their overriding concern to put patient quality-of-life first. "I firmly believe that for someone extremely undernourished, trying desperately to refeed them is already a stupid idea-it just won't work" (Doctor \#3). The time factor thus emerges as essential, and for many geriatricians, as soon as the patient is taking even a little food on board, the decision to engage a nutritional intervention can be pushed back to later. "The crux of the issue in AGCU care is that even if you register severe undernutrition, regardless of the criteria you base it on, if food intakes are any good at all, then you can use up time to attempt to recorrect through oral feeding" (Doctor \#2).

\section{Preconceptions and perceptions of care staff}

The care staff tend to consider that a drop in food intakes is a normal sign of the natural ageing process, culminating in a form of anorexia synonymous with refusal of care: "the person is in her early nineties, you can see that she's tired of life and that the refusal to eat is her way of showing that she's had enough" (RN 1 ). This means that nutrition management decisionsregardless of whether for or against intervention-are often misunderstood, and can sometimes even add a burden of distress to care staff teams who want to be kept informed and their voice heard. "Me, if there's things I struggle to accept, I go and see the doctors, because if no-one tells me what's happening, I can't let it go" (RNCA \#11) "sometimes, as care staff, we really struggle when we see someone for weeks, like the guy who died this morning, for weeks he wasn't eating, and we kept telling them, telling them [...] So you get the impression no-one listened to a word we say, nothing gets done about it, that you're letting them starve to death". (RNCA \#9) That said, even in the situations where the care staff feel disarmed, there is still some ambivalence over the NGT. "I must say, I do find that at it's still a procedure that is quite violent, in that it's, after all, still an invasive procedure" (RN \#1) The geriatric care teams remain underfamiliarized with using it, and they often experience placing the NGT as an assault on the patient. "I'm still not real comfortable with it, becausewell, sure, I haven't placed many, and as interventions go, it can't be easy to live with" (RN \#4). Today's better hardware has nevertheless brought tangible progress, which the teams readily accept. "You have these special catheters now, with guidewires, that make procedure so much easier" (RN \#2).

\section{Fear of complications}

Geriatrics, more than any other ward, seems to suffer the stigma of the incidence of complications. "It's mainly inhaling stuff, yeah-I had the case of a patient who suffered a major aspiration pneumonia, which he never recovered from"(Doctor \#10) "You're often reluctant to place catheters-you can't just place catheters and be done, without mulling it over" (Doctor \#1).

\section{Difficulties in practice}

Interviewees raised several difficulties unique to geriatric care, such as tube feeding at night, the risk of prolonging the hospital stay and difficulties homefront continuation of care, although they also gave some positive feedback. "I'm personally not too happy with them being fed at night because there's one nurse for 33 patients" (RN \#2). "The NGT is not something you can go back home with-not unless you're on in-home care" (Doctor \#4) "I have already had two reports back from a care provider following her at home, and with that, she's absolutely fine with her NGT" (Doctor \#10).

\section{The alternative-parenteral nutrition}

Parenteral nutrition (PN) is not perceived as an alternative to NGT feeding, and appears to be rarely used in practice. "Personally I never put a patient on parenteral. Either I decide to talk about the nasogastric tube and then a Percutaneous Endoscopic Gastrostomy (PEG), or it's a no." (Doctor \#2) Some doctors find that PN may be indicated when the care plan has not be clearly established or when it is difficult to gauge the patient's acceptance. "Why not use parenteral nutrition more in acute cases when you're not sure of where you're going, rather than placing a NGT?"(Doctor \#6).

\section{Factors connected to the elderly population}

\section{Very old age and unreasonable obstinacy}

Many doctors and care staff alike challenge the ethical soundness of starting this type of treatment in very 
old age, when patients are dependent on care and life expectancy is short, often to the point that it crosses the border into unreasonable obstinacy. "You have to admit that in paediatrics you are thinking about a life ahead, so there's nothing distressing about putting a feeding tube on a baby in neonatal care because it's just something you have to do to give them every chance of making it through, whereas in geriatrics you tend to hold back on it, because is NGT really worth it, is the patient consenting?" (Doctor \#4) Practitioners regularly struggle with lingering doubts over the outcome of this type of care protocol. "Is it really going to bring the patient some kind of relief, because we've all had times when we've set up nutrition in patients who deceased shortly after." (Doctor \#10)

\section{Cognitive disorders}

The prevalence of cognitive disorders in the geriatriccare population emerges as a real barrier to the use of EN. "They're just going to rip it out, because they just don't understand what's going on." (Doctor \#7) “When you have to fit wrist restraints just to keep the NGT in place, I consider that we've lost all sight of common sense and that we're bordering on abuse to get someone feeding" (Doctor \#10). The doctors remain well aware of the risk of under-evaluating the right indications for enteral nutrition. "You get so conditioned by all these patients who are very old or have cognitive disorders [...] it prompts behaviours in patients who would likely benefit and we maybe end up overcompensating and excluding them." (Doctor \#5)

\section{The long-term-care perspective}

The geriatric doctors appear to fear the withdrawal of the NGT or the risk of having to move to a long-term PEG they feel is unreasonable. "You are withdrawing food, which in people's minds means you are killing the patient [...] Withdrawing it is a really tough call." (Doctor \#6) "Why didn't we put him on PEG? You have to do something to stop short of overaggressive obstinacy [...] there are situations where you have to know when it's time to stop, because once you take the road of a nutrition management process, after there's no turning back." (Doctor \#4)

\section{Patient comfort and quality of life}

The staff struggle to square integrating an invasive protocol like NGT feeding into a care plan where the goals are supposed to be the patient's comfort and quality of life. "You feel like you're creating them unnecessary hassle, given that in 10 days' time, they'll be back at home." (Doctor \#5)

\section{Discussion}

\section{Main findings}

The objective of this study was to analyze the knowledge and practices governing implementation of nasogastric tube feeding as an enteral nutrition support measure in AGCU wards. Our findings highlight a number of factors that create a disconnection between real-life bedside care practices and guidelined medical nutrition management. Even though practitioners can lead on HAS and ESPEN guidelines, our study effectively shows that the issue remains fraught with complexity-a complexity that can be translated into several explanatory concepts to help better grasp the difficulties faced by geriatric health care teams.

Foremost, the geriatric health care teams are essentially trained in the management of cognitive disorders and end-of-life care, which revolves around a comprehensive care plan approach focused on the patient's comfort and quality of life. Our results do show that undernutrition is perceived as a latent phenomenon, commonly emerging in elderly patients, and patterned perhaps more as a comorbidity to be dealt with than a disease to be treated. The most common care consists in screening and oral nutrition, and geriatricians often think that Subacute Care and Rehabilitation is a better ward for nutrition care than AGCU. NGT feeding does not appear to be considered a solution to improve way to improved protein-energy intakes. It does feature in the therapeutic arsenal of geriatric medicine, but does not appear to get used unless to support adjuvant care for other diseases when framed within a comprehensive care plan (13). It is perceived as an invasive, aggressive therapeutic measure, which increases the risk of confusion, and often leads geriatric care teams to feel they are going against their primary goals of care, i.e. the patient's comfort and quality of life.

Then, when its use seems needed, several concepts converge to influence medical decision-making in the AGCU ward, and thus determine certain preconditions. Information and consent are vital yet insufficient factors. Active patient participation, which goes further than a straight yes/no consent, is absolutely pivotal and will be dictated by how the NGT intervention plan is presented to the patient, how far the patient can trusts the doctor and how the patient can understand the information. Another concept is the role of the primary caregivers. Even though the medical decision has always been grounded in the wishes of the patient, it appears essential to have their collaborative involvement. The long-termcare perspectives can also prove problematic. Firstly, organizing EN at home for care-dependent patients can prove a real hurdle. Secondly, the uncertainty about the patient's progress may lead to fear of a form of unreasonable medical care with the risk of becoming forced to look at a PEG. Last but not least, ethical factor remains a key factor being systematically addressed in 
this population where life expectancy is uncertain and prevalence of cognitive disorders is high. Consequently, the expected benefit of an NGT intervention seems uncertain for care teams and has to be more clear whereas they affraid over crossing the border into unreasonable obstinacy. Thus, the care staff teams-like the doctorsvoice their need for a medical decision to be taken by multidisciplinary collegial consensus.

The circumspective position manifested by the geriatricians is probably legitimate given the potential consequences of an NGT in the most frail elderly (16). While the guidelines do not rule out NGT feeding as a very-short-term measure in patients with cognitive impairment, extended long-term delivery of EN via PEG is not advisable $(1,12)$. The ESPEN prompts practitioners to think hard about the expected benefits of EN, and the HAS is equally prudent, advising EN only when expected benefit is considered to outweigh the procedure-related risks $(1,12)$. Furthermore, the legal framework tends to improve comfort-only and support care first $(17,18)$. Even though the guidelines argue for enteral nutritional support to maintain normal intakes $(1,11,12)$, the literature fails to confirm any real benefit in very old inpatients outside of certain indications for orthopedic surgery or as treatment for pressure ulcers (19-22). Nutritional interventions studies seems effective but often concern younger patients, and few of them bring evidence that would encourage geriatricians to start a nutritional intervention in the oldest age-bracket patients (23-25). A recent review of the literature confirms the struggle to characterize the groups of elderly inpatients most likely to benefit from nutritional support (26). However, the geriatric care teams appear too undertrained on EN to be able to confidently assess this benefit-risk ratio and they have probably to expand their use of EN. Some of the concepts highlighted should be considered in order to initiate an EN as part of a global care project.

The qualitative approach adopted here enabled us to explore complex phenomena beyond the grasp of other scientific approaches. However, this method of inquiry does impose certain limitations, that we sought to minimize here using COREQ criteria (15).

\section{Conclusion}

Active nutrition management for undernourished elderly patients in the AGCU is problematic as a process when the goals of the care plan are the patient's comfort and quality of life. Although various sets of recommendations have been released to help to guide clinicians in their decision-making, there is no solid data to confidently assert the benefit of EN in very-old-age patients and confirm the grounds for its indication. The good use of NGT in AGCU remains to be defined despite the guidelines of ESPEN and HAS.
Ethical standards: The study secured approval from a french committee for the protection of human subjects.

Conflict of Interest: The authors have no conflict of interest.

\section{References}

1. Haute Autorité de Santé - Stratégie de prise en charge en cas de dénutrition protéino-énergétique chez la personne âgée. has-santé.fr. http: / / www.has. sante.fr/portail/jcms/fc $1249588 / \mathrm{fr} /$ accueil-2012

2. Potter J, Klipstein K, Reilly JJ, Roberts M. The nutritional status and clinical course of acute admissions to a geriatric unit. Age Ageing. 1995;24(2):131-6.

3. Patel MD, Martin FC. WHY DON'T ELDERLY HOSPITAL INPATIENTS EAT ADEQUATELY? J Nutr Health Aging. 2008;12(4):227-31.

4. Bonnefoy M, Berrut G, Lesourd B, Ferry M, Gilbert T, Guérin O, et al. Frailty and nutrition: searching for evidence. J Nutr Health Aging. 2015;19(3):250-7.

5. Galanos AN, Pieper CF, Cornoni-Huntley IC, Bales CW, Fillenbaum GG. Nutrition and function: is there a relationship between body mass index and the functional capabilities of community-dwelling elderly? J Am Geriatr Soc. 1994;42(4):368-73.

6. Paillaud E, Herbaud S, Caillet P, Lejonc J-L, Campillo B, Bories P-N. Relations between undernutrition and nosocomial infections in elderly patients. Age Ageing. 2005;34(6):619-25.

7. Herrmann FR, Safran C, Levkoff SE, Minaker KL. Serum albumin level on admission as a predictor of death, length of stay, and readmission. Arch Intern Med. 1992;152(1):125-30.

8. Sullivan DH. The role of nutrition in increased morbidity and mortality. Clin Geriatr Med. 1995;11(4):661-74.

9. Wallace JI, Schwartz RS, LaCroix AZ, Uhlmann RF, Pearlman RA. Involuntary weight loss in older outpatients: incidence and clinical significance. J Am Geriatr Soc. 1995;43(4):329-37.

10. Payette H, Coulombe C, Boutier V, Gray-Donald K. Weight loss and mortality among free-living frail elders: a prospective study. J Gerontol A Biol Sci Med Sci. 1999;54(9):M440-5.

11. Bouteloup C, Thibault R. Arbre décisionnel du soin nutritionnel. Nutr Clin Metabol 2014;28(1):52-6.

12. Volkert D, Berner YN, Berry E, Cederholm T, Coti Bertrand P, Milne A, et al. ESPEN Guidelines on Enteral Nutrition: Geriatrics. Clin Nutr 2006; 25(2): 33060.

13. Bruhat A, Bos C, Sibony-Prat J, Bojic N. L'assistance nutritionnelle chez les malades âgés dénutris. Presse Med. 2000 ;29(39) :2191-201.

14. Jaafar MH, Mahadeva S, Subramanian P, Tan MP. Perceptions of Healthcare Professionals on the Usage of Percutaneous Endoscopic Gastrostomy in a Teaching Hospital from a Middle-Income South East Asian Country. J Nutr Health Aging. 2017;21(4):473-479.

15. Tong A, Sainsbury P, Craig J. Consolidated criteria for reporting qualitative research (COREQ): a 32-item checklist for interviews and focus groups. Int J Qual Health Care. 2007;19(6):349.

16. Lubart E, Leibovitz A, Dror Y, Katz E, Segal R. Mortality after nasogastric tube feeding initiation in long-term care elderly with oropharyngeal dysphagia-the contribution of refeeding syndrome. Gerontology. Karger Publishers; 2009;55(4):393-7.

17. Loi N. Loi: 303 du 4 mars 2002 relative aux droits des malades... - Google Scholar. Journal officiel; 2002.1 p.

18. Aubry R, Puybasset L, Devalois B, Morel V, Viallard M-L. Loi du 2 février 2016 créant de nouveaux droits en faveur des malades et des personnes en fin de vie : analyse et commentaires. Médecine Palliative : Soins de Support Accompagnement - Éthique. 2016;15(3):165-70.

19. Bastow MD, Rawlings J, Allison SP. Benefits of supplementary tube feeding after fractured neck of femur: a randomised controlled trial. Br Med J 1983;287(6405):1589-92.

20. Beattie AH, Prach AT, Baxter JP, Pennington CR. A randomised controlled trial evaluating the use of enteral nutritional supplements postoperatively in malnourished surgical patients. Gut. 2000;46(6):813-8.

21. Hartgrink HH, Wille J, König P, Hermans J, Breslau PJ. Pressure sores and tube feeding in patients with a fracture of the hip: a randomized clinical trial. Clin Nutr. 1998;17(6):287-92.

22. Stratton RJ, Ek A-C, Engfer M, Moore Z, Rigby P, Wolfe R, et al. Enteral nutritional support in prevention and treatment of pressure ulcers: a systematic review and meta-analysis. Ageing Res Rev. 2005;4(3):422-50.

23. Milne AC, Avenell A, Potter J. Meta-analysis: protein and energy supplementation in older people. Ann Intern Med. 2006;144(1):37-48.

24. Feldblum I, German L, Castel H, Harman-Boehm I, Shahar DR. Individualized nutritional intervention during and after hospitalization: the nutrition intervention study clinical trial. J Am Geriatr Soc. 2011;59(1):10-7.

25. Hegerová $P$, Dědková $Z$, Sobotka L. Early nutritional support and physiotherapy improved long-term self-sufficiency in acutely ill older patients. Nutrition. 2015;31(1):166-70.

26. de van der Schueren MAE, Wijnhoven $\mathrm{HAH}$, Kruizenga HM, Visser M. A critical appraisal of nutritional intervention studies in malnourished community dwelling older persons. Clin Nutr. 2016;35(5):1008-14. 